Check for updates

Received 18th May 2017

Accepted 10th July 2017

DOI: $10.1039 / c 7 r a 05636 b$

rsc.li/rsc-advances
Cite this: RSC Adv., 2017, 7, 36644

\section{Synthesis of copper sulfide nanoparticles and evaluation of in vitro antibacterial activity and in vivo therapeutic effect in bacteria-infected zebrafish $\dagger$}

\begin{abstract}
Khan Behlol Ayaz Ahmed and Veerappan Anbazhagan (iD *
In this study, a facile method to synthesize non-toxic copper sulfide nanoparticles was reported, and the antibacterial activity of the nanoparticles in infected zebrafish was evaluated. Transmission electron microscopy showed that the CuS NPs are spherical in shape with a size range from 10 to $25 \mathrm{~nm}$. FTIR spectra revealed that the CuS NPs were stabilized by N-lauryltyramine. CuS NPs exhibit very good antibacterial activity against Gram-negative and Gram-positive bacteria, and the minimum inhibitory concentration was determined as $12.5 \mu \mathrm{M}$. In vitro mechanistic studies revealed that CuS NPs kill the bacteria by damaging their cell membranes and producing reactive oxygen species. Therapeutic activity of CuS NPs was tested in bacteria-infected zebrafish. The route of administration of CuS NPs was via an injection and medicated bath. Both routes of drug administration were suitable to cure the fish from bacterial infection. Bacterial colony count assay revealed that the CuS NPs depleted the infectious bacteria from the fish body within $24 \mathrm{~h}$. Strikingly, CuS NPs in concentration eight times than the MIC did not show toxicity in the liver and brain of zebrafish. Moreover, the NPs exhibited good hemocompatibility with human red blood cells. Our study demonstrated for the first time that CuS NPs are a safe antibacterial agent, and medicated bath with zebrafish is a hassle-free model for testing the antibacterial activity of nanoparticles.
\end{abstract}

\section{Introduction}

The growing number of identified multi-drug-resistant bacterial strains are a major concern in modern medicine. ${ }^{\mathbf{1 , 2}}$ Multi-drug resistance (MDR) cannot be curtailed with standard drug treatments and requires high-dose administration of multiple drugs that often leads to undesirable side effects. ${ }^{3,4}$ As an alternative to conventional antibacterial therapy, metal nanoparticles such as $\mathrm{Au}, \mathrm{Ag}, \mathrm{Cu}, \mathrm{Pt}, \mathrm{Pd}, \mathrm{ZnO}, \mathrm{TiO}_{2}, \mathrm{Bi}_{2} \mathrm{O}_{3}, \mathrm{CuO}$, and $\mathrm{Fe}_{2} \mathrm{O}_{3}$ have been explored as antibacterial agents. ${ }^{5-11}$ Of late, materials like $\mathrm{Bi}_{2} \mathrm{O}_{3}$, Ce-doped $\mathrm{Bi}_{2} \mathrm{MoO}_{6}$, Ag-decorated $\mathrm{Bi}_{2} \mathrm{O}_{3}$, $\mathrm{TiO}_{2}-\mathrm{Bi}_{2} \mathrm{WO}_{6}$, and $\mathrm{Fe}-\mathrm{TiO}_{2}$ have been used for photocatalytic inactivation of bacteria. ${ }^{12-15}$ The precursors to synthesize copper nanoparticles are more readily available than those to synthesize other metal nanoparticles; therefore, developing an antibacterial agent with CuNPs is cost effective. ${ }^{16}$ Although CuNPs exhibit good antibacterial activity, they are highly toxic when tested in the zebrafish animal model. ${ }^{17}$ At the same time, at

Department of Chemistry, School of Chemical and Biotechnology, SASTRA University, Thanjavur - 613 401, Tamil Nadu, India. E-mail: anbazhagan@scbt.sastra.edu; anbugv@gmail.com

$\dagger$ Electronic supplementary information (ESI) available: Zeta and particle size analysis, turbidimetry, all bacterial colony count assay, toxicology. See DOI: 10.1039/c7ra05636b lower concentrations, these NPs act as efflux pump inhibitors and prevent biofilm formation. ${ }^{18,19}$ The beneficial nature of CuNPs can be exploited by minimizing their toxicity and maximizing their therapeutic window through proper surface modification. For example, we have recently shown that the sulfidation of CuNPs decreases their toxicity. ${ }^{\mathbf{1 7}}$

Copper sulfide (CuS), a P-type semiconductor, has received attention recently due to its potential application in various fields, including thermoelectrics, solar cells, ion storage, batteries, and photovoltaic, photocatalytic, and chemical sensing applications. ${ }^{20-24}$ In addition to semiconductor-based application, CuS NPs have been emerging as a promising platform for photothermal cancer therapy, biomolecular sensing, and molecular imaging. ${ }^{25-27}$ Herein, we demonstrate the antibacterial activity of CuS NPs against Gram-positive and Gram-negative pathogenic bacteria. CuS NPs kill bacteria through the production of reactive oxygen species (ROS) and by disturbing the bacterial membranes. There are numerous reports about the antibacterial activity of various metal NPs including CuS NPs, ${ }^{28-30}$ but most are basic evaluations and their efficacy in an infected animal model has been rarely reported. Another bottleneck in the usage of NPs is their toxicity in biological systems, which delays the advancement of these materials for clinical applications. ${ }^{31-33}$ The paucity was 
addressed in this study by curing bacteria-infected zebrafish using CuS NPs. The zebrafish animal model is an important model in biomedical research because zebrafish share several common biological pathways with humans and are $80 \%$ genetically identical to humans. ${ }^{34-37} \mathrm{CuS}$ NPs stop bacterial proliferation in zebrafish and cure them from microbial infection. The CuS NPs kill the bacteria, exhibit low toxicity and maintain good hemocompatibility. Notably, the CuS NPs not only cure the infection but also disinfect the pathogens present in water.

\section{Results and discussion}

\subsection{Synthesis of copper sulfide nanoparticles}

Copper sulfide nanoparticles were prepared from $N$-lauryltyramine capped copper nanoparticles (NLTA-CuNPs). The freshly prepared NLTA-CuNPs on reaction with sodium sulfide produced a color change from brown to olive green, indicating the formation of CuS NPs (Fig. 1). The quantitative chemical composition of copper and sulfide in our preparation was estimated by energy dispersive X-ray spectroscopy (EDX). The EDX analysis was carried out only for $\mathrm{Cu}$ and $\mathrm{S}$; the average atomic percentage ratio of $\mathrm{Cu}: \mathrm{S}$ was $42: 58$, showing that the CuS NPs were in a good stoichiometric ratio (Fig. S1 $\dagger$ ).

The size and morphology of the CuS NPs were measured by TEM analysis, which clearly revealed that the NPs are spherical in shape with a size range from 10 to $25 \mathrm{~nm}$ (Fig. 2A). Highresolution TEM showed a metallic fringe pattern (Fig. 2B). The selected area electron diffraction (SAED) pattern showed ring patterns, suggesting the crystalline nature of NPs (inset of Fig. 2B). The size of the NPs was further verified by a particle size analyzer (PSA), and it was observed that the size obtained from PSA (70.6 nm) differed from that shown via TEM (Fig. S2 $\dagger$ ). The polydispersity index (PDI) of NLTA-CuS NPs was 0.340. It is well known that polydispersity of the NPs can distort PSA. ${ }^{38}$ At

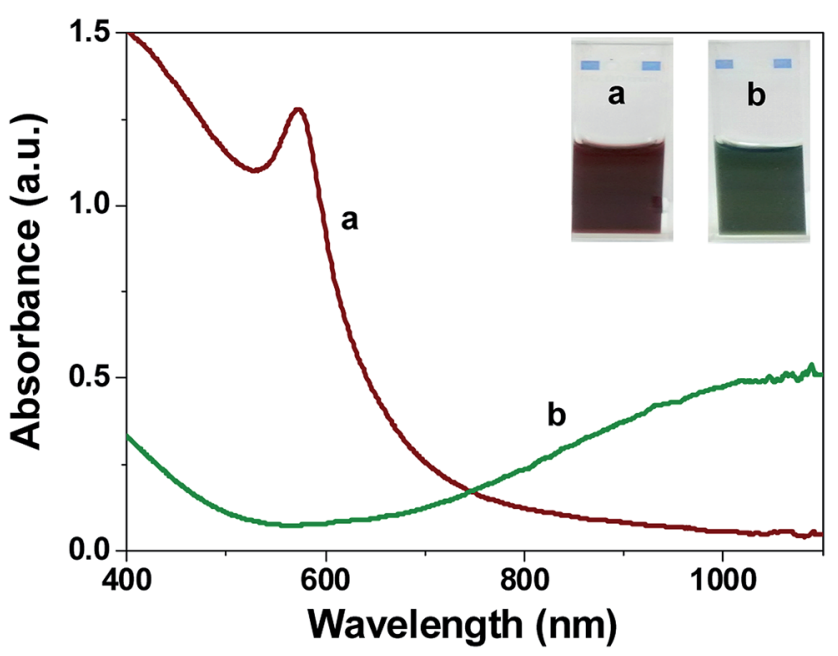

Fig. 1 UV-visible spectra of (a) NLTA-CuNPs and (b) NLTA-CuS NPs. Inset corresponds to photographs of (a) (CuNPs are brown) and (b) (CuS NPs are olive green). The disappearance of CuNP SPR maximum at $580 \mathrm{~nm}$ and the appearance of peak above $1000 \mathrm{~nm}$ indicate the formation of CuS NPs.
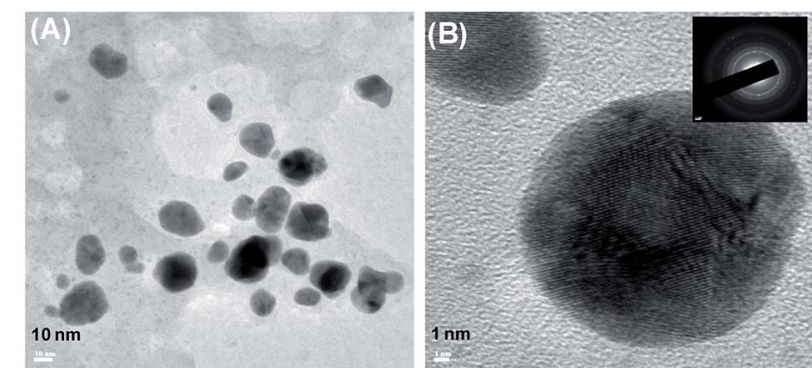

(C)

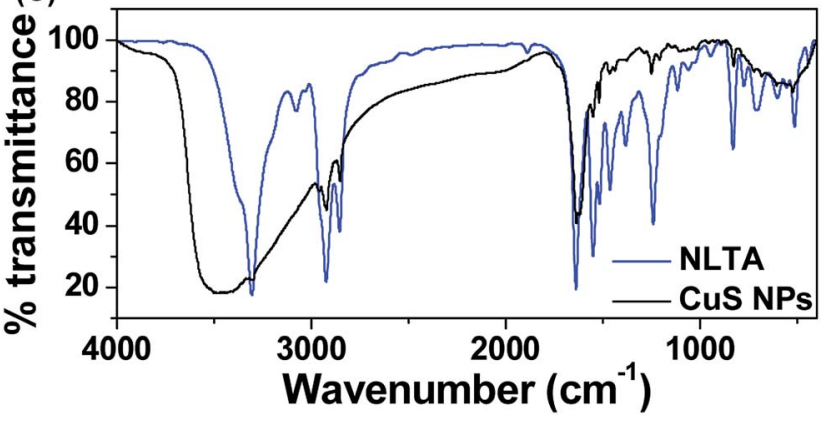

Fig. 2 (A) Transmission electron microscopy images of CuS NPs, (B) high-resolution TEM images showing the fringe pattern of the particles, inset corresponds to SAED pattern, which confirms the crystalline nature of CuS NPs, and (C) FTIR spectra of NLTA (blue line) and NLTAcapped CuS NPs (black line).

the same time, the difference in the size can also be attributed to the presence of the $N$-lauryltyramine capping agent on the NP surface because TEM measured the size of the individual NPs, whereas PSA took into account the hydrodynamic ligand shell too. To validate our claim, FTIR spectra of NLTA and CuS NPs were measured (Fig. 2C). The IR spectra of NLTA showed a sharp band at $3305 \mathrm{~cm}^{-1}$ for $-\mathrm{NH}$ and $-\mathrm{OH}$ stretching vibrations of NLTA. The peak at 2920 and $2852 \mathrm{~cm}^{-1}$ was attributed to $-\mathrm{CH}$ symmetric and asymmetric stretching, respectively. The characteristic peaks of amide linkage were observed at $1638 \mathrm{~cm}^{-1}$ (amide I) and $1548 \mathrm{~cm}^{-1}$ (amide II). Methylene bending and rocking bands were observed near $1463 \mathrm{~cm}^{-1}$ and $715 \mathrm{~cm}^{-1}$, respectively. The IR spectra of CuS NPs showed peaks at 3470 , 2918, 2851, 1637, 1548, 1466 and $720 \mathrm{~cm}^{-1}$, which correspond to asymmetric and symmetric stretching vibration of NLTA molecules. The broadening and shifting of $-\mathrm{OH} /-\mathrm{NH}$ stretching vibrations $\left(3470 \mathrm{~cm}^{-1}\right)$ were recorded for the CuS NPs, suggesting that the NLTA molecules were successfully coated on CuS NPs, leading to the NPs having good solubility and sufficient stability. Zeta potential estimates for NLTA-stabilized CuS NPs were $-25.3 \mathrm{mV}$ (Fig. S3†), suggesting that the NP boundaries were well separated to prevent agglomeration.

\subsection{Antibacterial activity of CuS NPs}

In vitro antibacterial susceptibility of CuS NPs was evaluated against two Gram-negative bacteria ( $E$. coli and A. hydrophila) and two Gram-positive bacteria (B. subtilis and $S$. aureus). Resazurin microplate assay (REMA) was adopted for determining the minimum inhibitory concentration (MIC), the lowest concentration of the antibacterial agent to prevent the 
growth of a microorganism. Live bacterial cells irreversibly reduce resazurin to resorufin, displaying a pink color with strong fluorescence at $580 \mathrm{~nm}$, whereas dead cells show blue color with weak fluorescence. Results shown in Fig. 3 show that the bacterial cells exposed to CuS NPs showed weak fluorescence upto $12.5 \mu \mathrm{M}$, after which the fluorescence increased, indicating the existence of viable cells and that the MIC is $\mathbf{1 2 . 5}$ $\mu \mathrm{M}$ (Fig. 3). MIC determined by conventional turbidimetry is consistent with that determined by REMA (Fig. S5 $\dagger$ ). The antibacterial activity of CuS NPs was also tested by the conventional zone of inhibition (ZOI) method. ZOI measures the killing efficiency of the NPs against the tested bacteria. Results demonstrated that $10 \mu \mathrm{M}$ is sufficient to kill the bacteria; however, killing efficiency increased with concentration of CuS NPs (Fig. S6 $\dagger$ ). Based on these results, $10 \mu \mathrm{M}$ was chosen for further studies.

\subsection{In vivo antibacterial activity}

Having observed promising antibacterial activity against Grampositive and Gram-negative microorganisms, we set out to investigate the therapeutic efficacy of CuS NPs in an animal model. To this end, we infected zebrafish intramuscularly with an optimized concentration of microbes (see ESI $\dagger$ ) and initiated treatment with CuS NPs. Two treatment methods were adopted, (i) intramuscular injection treatment and (ii) medicated bath treatment.

For the injection method, fish were divided into two groups and each group contained five healthy fish. Group A and group B were infected intramuscularly with $10 \mu \mathrm{L}$ of microbes $(0.1$ $\mathrm{OD}_{660 \mathrm{~nm}}$ ) and allowed to live in normal tap water. After three hours of infection, only group B fish were injected with $10 \mu \mathrm{L}$ of CuS NPs $(10 \mu \mathrm{M})$. Group A fish infected with microbes slowed down in $6 \mathrm{~h}$ and finally succumbed to infection in 8-10 h. In contrast, group B fish treated with CuS NPs remained alive and their behaviour was similar to that of uninfected fish. To understand how CuS NPs cure the fish from infection, we sacrificed the fish from both groups at regular time intervals and collected muscle tissues through dissection. The dissected

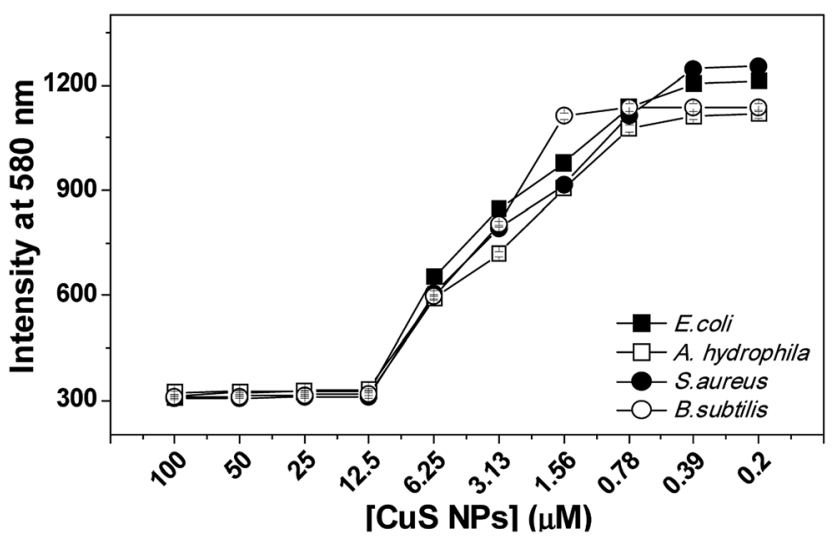

Fig. 3 REMA assay. Below $12.5 \mu \mathrm{M}$, fluorescence intensity was observed in all the tested bacteria. Experiments were performed in triplicate. tissues were homogenized and diluted appropriately in PBS buffer and plated on an agar plate. The plates were incubated for $24 \mathrm{~h}$ at $37^{\circ} \mathrm{C}$ and the number of bacterial colonies present in each group were estimated. Representative plates corresponding to $E$. coli infection and treatment with CuS NPs are shown in Fig. S7A and B, $\uparrow$ respectively. As noted from Fig. 4A, both Gramnegative and Gram-positive strains without NP treatment exhibit a typically high number of bacterial colonies, while group B shows considerably depleted bacterial colonies after $24 \mathrm{~h}$ (Fig. 4B). This indicates that CuS NPs kill the microbes and save the zebrafish from infection.

Injection method is painful and requires a skilful technician to administer the drug. Moreover, it is difficult to identify individually infected fish from a big pool. Thus, it is imperative to develop an antibacterial agent to treat the infected fish in the entire pool without affecting the uninfected fish. To meet the demand, we initiated the antibacterial study with water containing CuS NPs (called as a medicated bath). Fish were divided into two groups and infected intramuscularly with $10 \mu \mathrm{L}$ of microbes $\left(0.1 \mathrm{OD}_{660} \mathrm{~nm}\right)$. Group A fish were allowed to live in normal tap water and group B fish were allowed to live in tap water containing $10 \mu \mathrm{M}$ of CuS NPs. Group A fish died in 8-10 h
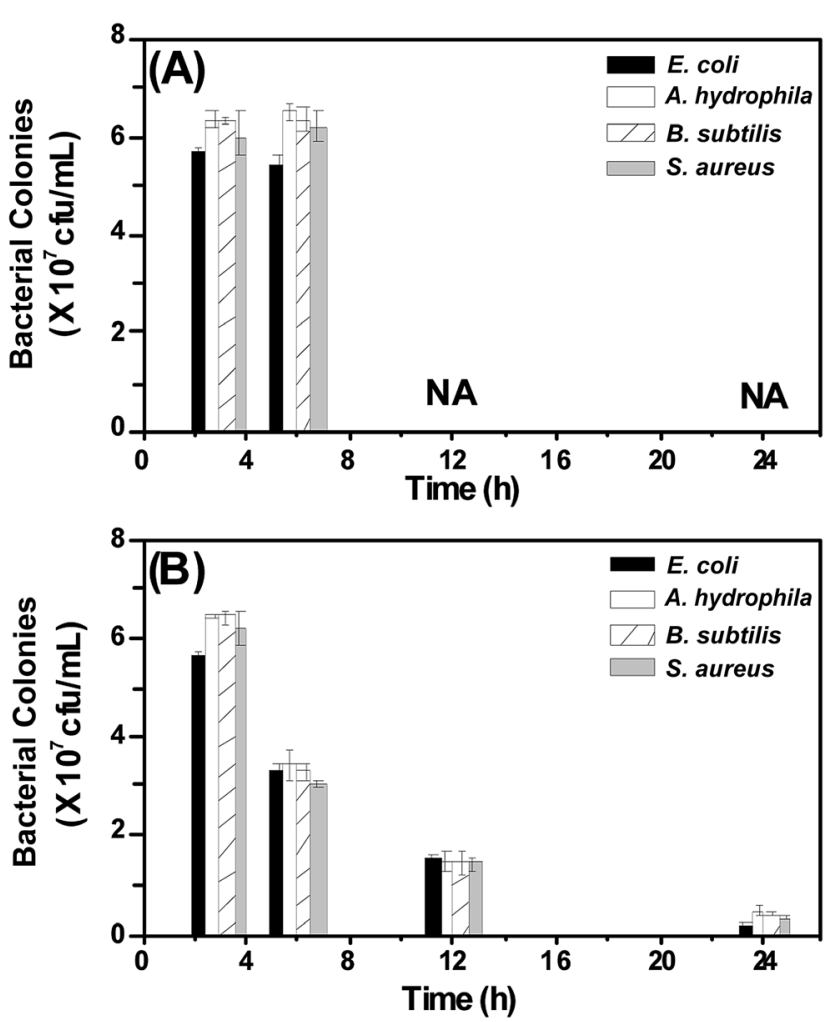

Fig. 4 Injection method. Bacterial colonies are formed on an LB agar plate. Observations of muscle tissues of the fish: (A) viable bacteria cells collected from the infected fish. NA indicates that the fish are dead at that time point and (B) viable bacteria cells remained in the muscle after treatment with CuS NPs. Muscle tissues obtained by sacrificing fish at a definite time point were homogenized, diluted $10^{-4}$ times and plated $(50 \mu \mathrm{L})$ on an LB agar plate. After $24 \mathrm{~h}$, fish treated with CuS NPs were nearly free from bacterial colonies, and thus survived. Experiments were performed in triplicate. 
due to the severity of infection. Interestingly, group B fish survived the infection and started behaving similar to uninfected fish. In order to understand the antibacterial activity of CuS NPs, the muscle tissues of the fish were dissected and analyzed for bacterial colonies. As shown in Fig. 5 and $S 8, \uparrow$ the medicated bath of CuS NPs halts the proliferation of Gramnegative and Gram-positive strains and cures the zebrafish.

\subsection{Antibacterial mechanism of CuS NPs}

To understand the antibacterial mechanism of CuS NPs, we evaluated the morphology changes of bacteria via scanning electron microscopy. About $0.1 \mathrm{OD}_{660 \mathrm{~nm}}$ of $E$. coli were incubated with $10 \mu \mathrm{M}$ of CuS NPs for $12 \mathrm{~h}$ and imaged via SEM. The cell walls of the bacteria treated with CuS NPs are wrinkled and damaged, while the untreated cells are smooth, rod-shaped with intact cell walls (Fig. 6A and B).

In addition, the integrity of the bacterial membranes was also examined by dual acridine orange/ethidium bromide staining (AO/EB). AO, a membrane-permeable dye, stains live cells and displays green fluorescence, whereas EB can only pass through the damaged membrane of dead cells and stain nucleic acid to display red fluorescence. After incubation with $10 \mu \mathrm{M}$ of CuS NPs for $12 \mathrm{~h}$, the cells were stained with AO/EB mixture and examined by fluorescence microscopy. As shown in Fig. 6C, the
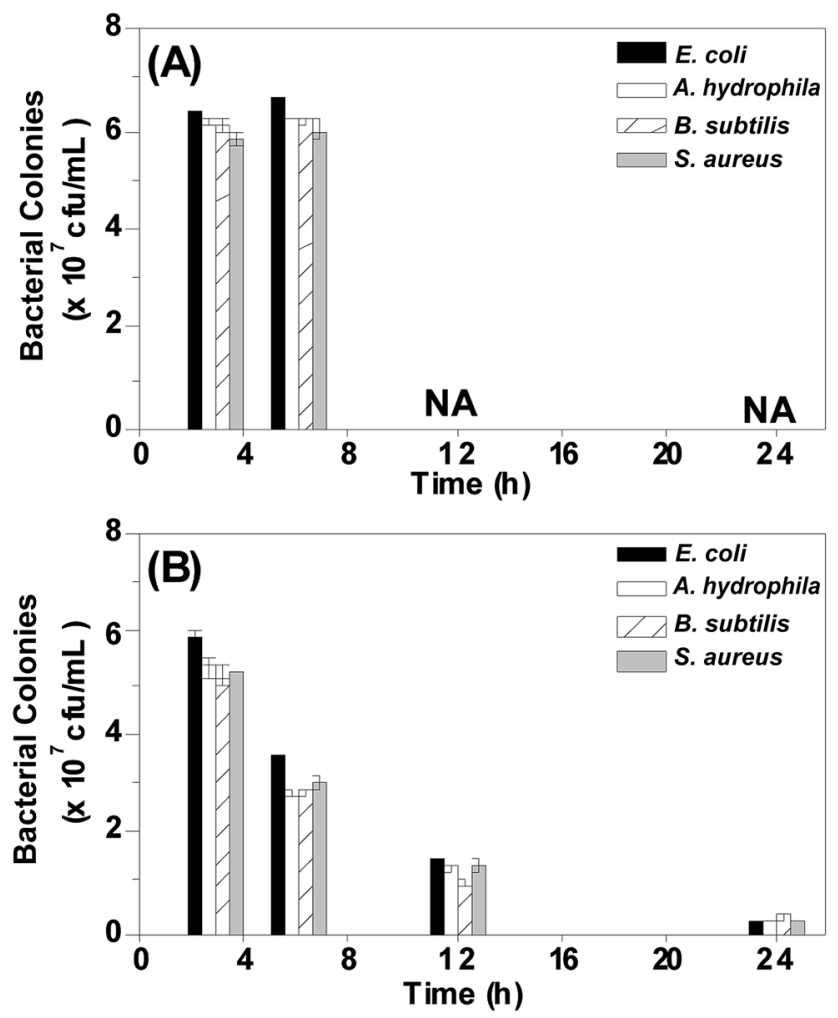

Fig. 5 Medicated bath method. (A) The infected fish and (B) the fish treated with medicated bath of $10 \mu \mathrm{M}$ CuS NPs. The cells were collected from the fish at the indicated time point and plated on an LB agar plate. After $24 \mathrm{~h}$, number of bacterial colonies decreased considerably and thus survived. NA indicates that the fish were dead at that time point. Experiments were performed in triplicate.
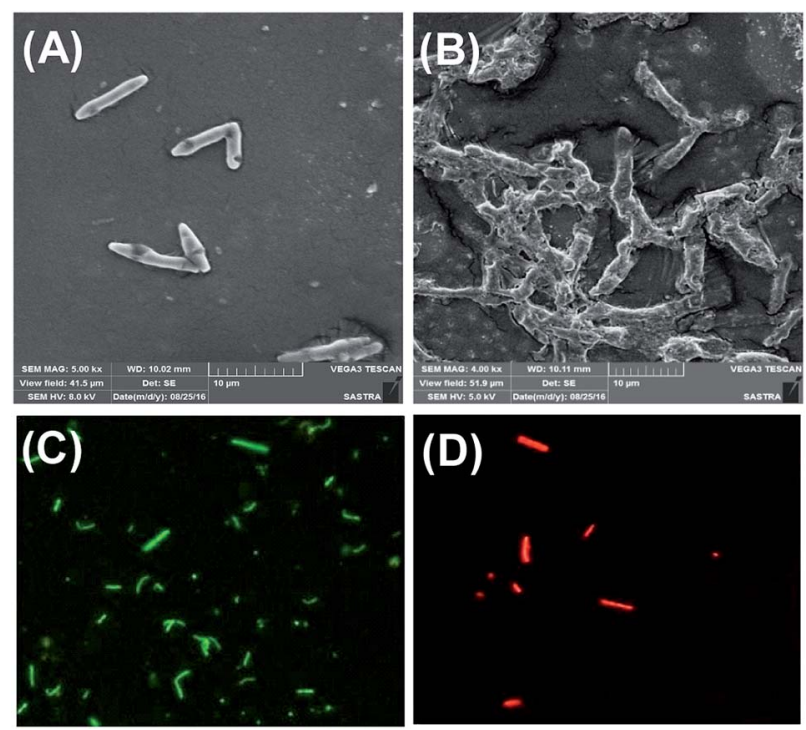

Fig. 6 Scanning electron micrograph of E. coli. (A) Untreated and (B) treated with $10 \mu \mathrm{M}$ CuS NPs. AO/EB staining of E. coli. (C) Untreated and (D) treated with $10 \mu \mathrm{M}$ CuS NPs. Live cells showed green fluorescence, while dead cells showed red fluorescence, indicating a compromised membrane and supporting the observed SEM micrograph (A) and (B), respectively.

untreated cells rarely show red fluorescence, but display green fluorescence, indicating that the cells are alive. In contrast, all the cells treated with NPs show red fluorescence, confirming the death of the cells and membrane damage (Fig. 6D).

Oxidative stress is one of the proposed antibacterial mechanisms of metal nanoparticles. ${ }^{39-41}$ The involvement of oxidative stress in antibacterial activity of CuS NPs was examined through the measurement of intracellular reactive oxygen species (ROS) production by $\mathrm{H}_{2}$-DCFDA assay. In the presence of ROS, nonfluorescent $\mathrm{H}_{2}$-DCFDA is oxidized and switches to greenfluorescent dichlorofluorescein (DCF). For this study, $\mathrm{H}_{2} \mathrm{O}_{2}$ was chosen as the positive control and the untreated cells as the negative control. As shown in Fig. 7A and B, weak ROS is generated in control cells, but CuS NPs and $\mathrm{H}_{2} \mathrm{O}_{2}$ trigger more production of ROS, as evidenced from the strong green fluorescence. Fig. 7C further shows the concentration-dependent increase in ROS production in the NP-treated cells, suggesting ROS-mediated cell death. At the same time, in comparison to the positive control (100\%), ROS production level in Gramnegative and Gram-positive varies from $61 \%$ to $65 \%$ when treated with $10 \mu \mathrm{M}$ CuS NPs. This implied that despite ROS production, membrane damage is also responsible for killing the bacteria.

The ROS production was further verified by measuring the production of malondialdehyde (MDA). The unsaturated fatty acids of cell membranes are highly vulnerable to ROS attack. The excess ROS produced will react with cell membranes and produce lipid peroxide radical, which on rearrangement will form MDA. The amount of MDA formed in the cells treated with CuS NPs was estimated using thiobarbituric acid assay. Fig. S9A $\uparrow$ shows the concentration-dependent increase in MDA 


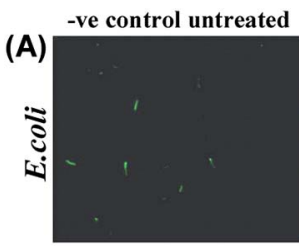

$10 \mu \mathrm{M}$ CuS NPs
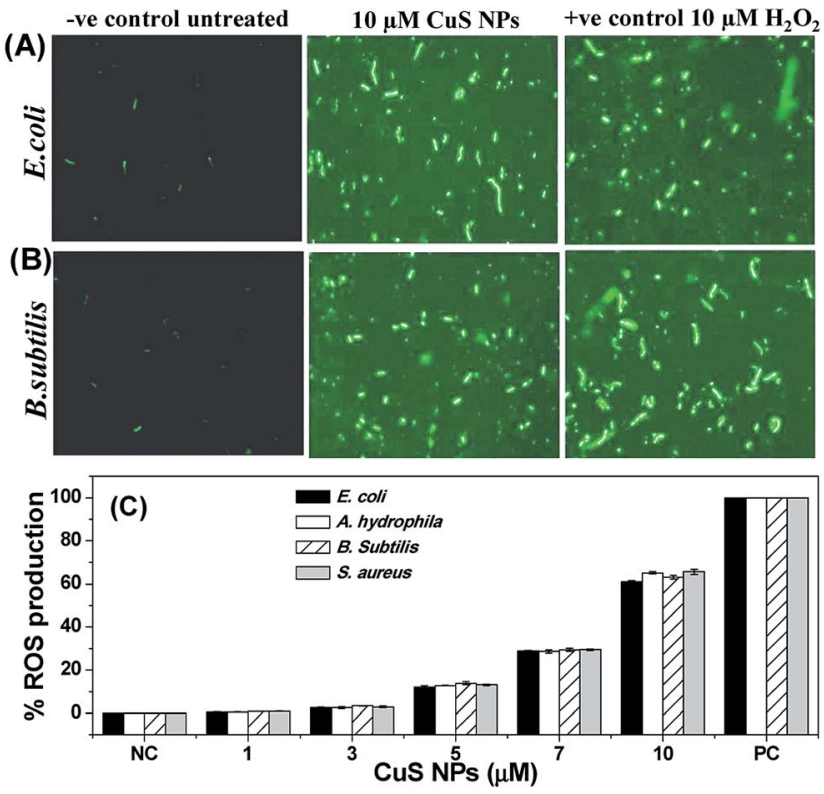

Fig. 7 ROS test. Fluorescence microscopic images (A) of E. coli and (B) $B$. subtilis before and after treatment with CUS NPs and positive control $\mathrm{H}_{2} \mathrm{O}_{2}$, followed by staining with $\mathrm{H}_{2}$-DCFDA. Strong green fluorescence demonstrated excess ROS production in treated cells. (C) Effect of CuS NPs on the formation of ROS in Gram-negative and Grampositive bacteria. Dichlorofluorescein diacetate $\left(D C F H_{2}-D A\right)$ was used as the fluorescence probe for detecting ROS. Hydrogen peroxide (PC) and untreated cells (NC) were used as positive and negative controls, respectively. Cells were treated with CuS NPs for $12 \mathrm{~h}$ and then incubated with $\mathrm{DCFH} \mathrm{H}_{2}$-DA for $2 \mathrm{~h}$. After that, the cells were lysed with an alkaline solution and the fluorescence was measured. Excitation $485 \mathrm{~nm}$ and emission - $525 \mathrm{~nm}$.

production in the NP-treated cells, supporting the generation of ROS. The intracellular ROS production was further investigated by measuring reduced glutathione concentration (GSH). GSH, a non-protein tripeptide, maintains the intracellular redox environment and protects the cells from oxidative damage by scavenging ROS. ${ }^{42}$ Thus, the maintenance of GSH oxidative defense is vital for cell survival. However, the generation of excess ROS oxidizes GSH to form disulfide. ${ }^{43}$ The amount of GSH present in the cells treated with CuS NPs was determined by DTNB assay. It was found that GSH concentration depleted in the treated cells with subsequent increase in CuS NP concentration (Fig. S9B $\dagger$ ). These results suggested that the interaction of CuS NPs with Gram-negative and Gram-positive bacteria triggered the intracellular ROS-mediated oxidative damage over the antioxidant defense and damaged the cell membrane, leading to cell death. A similar observation was reported in $E$. coli and $P$. aeruginosa, when they were treated with biosynthesized silver nanoparticles. ${ }^{44}$

\subsection{CuS NPs as a water disinfectant}

Having demonstrated the therapeutic efficacy of CuS NPs, we surmised that CuS NPs can also work as a general disinfectant. To test this hypothesis, two groups of fish were employed. $A$. hydrophila was chosen for this study because it is a fish-specific pathogen. Group A fish were exposed to water containing 0.1 $\mathrm{OD}_{660} \mathrm{~nm}$ of $A$. hydrophila. Contrary to the intramuscular infection, group A fish succumbed to infection in $33 \mathrm{~h}$, which suggests that the inherent defense mechanism present in the healthy fish delayed the waterborne bacterial infection. Group B fish, exposed to water containing $0.1 \mathrm{OD}_{660 \mathrm{~nm}} A$. hydrophila and $10 \mu \mathrm{M}$ CuS NPs, survived the infection.

At regular intervals, water from both the groups was collected and plated on an LB agar plate for counting the bacterial colonies. Strikingly, the water collected from group A showed higher number of bacterial colonies, which kept proliferating, as evidenced from the formation of uncountable bacterial mat on the LB agar plate after $6 \mathrm{~h}$ (Fig. S10A $\dagger$ ), whereas the water containing CuS NPs showed a time-dependent decrement in the bacterial colonies, indicating that CuS NPs kill the bacteria and prevent their proliferation (Fig. $\mathrm{S} 10 \mathrm{~B} \uparrow$ and 8). Unlike intramuscular infection, the fish exposed to water containing E. coli, B. subtilis and S. aureus were not infected. This could be attributed to the non-specific nature of the pathogens. However, the addition of CuS NPs killed the bacteria present in the water, as evidenced from the bacterial colony count assay (Fig. 8). These results suggested that CuS NPs may help prevent waterborne diseases.

\subsection{Evaluation of CuS NP toxicity}

The abovementioned studies demonstrate that the NLTA-CuS NPs have good therapeutic potential as an antibacterial agent and water disinfectant. However, to meet clinical standards, NPs should be less or non-toxic. To this end, we evaluated the toxicology parameters in zebrafish through assaying liver carboxylesterase (CES) and brain acetylcholinesterase (AchE) activity. The liver is an important organ for xenobiotic detoxification. Carboxylesterase is an enzyme activated during xenobiotic stress and involved in the hydrolysis of carboxylic esters. AchE catalyzes the breakdown of acetylcholine and other choline esters to facilitate function as a neurotransmitter; therefore, it can serve as a marker for neuronal toxicity. Strikingly, the treatment of zebrafish with CuS NPs at $100 \mu \mathrm{M}(8$ times the MIC) concentration had a negligible change in liver

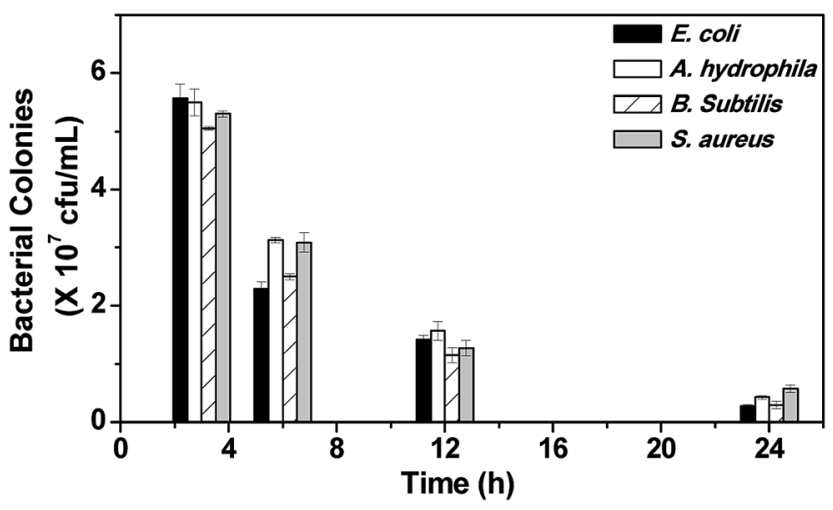

Fig. 8 Viable bacterial colonies present in water after treatment with $10 \mu \mathrm{M}$ CuS NPs. Diluted water $\left(10^{-4}\right.$ times) was used for LB agar plating. Experiments were performed in triplicate. 


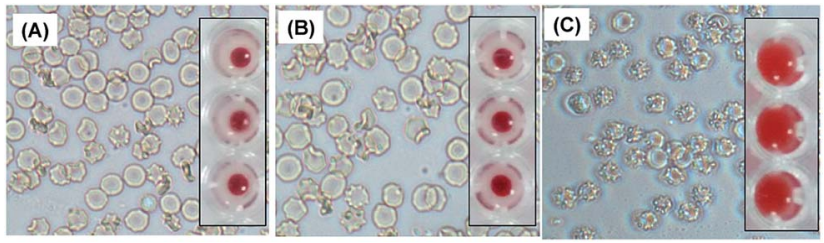

Fig. 9 Microscopic images of human RBCs. (A) Untreated-negative control, (B) treated with $100 \mu \mathrm{M}$ CuS NPs and (C) treated with $100 \mu \mathrm{M}$ $\mathrm{NH}_{4} \mathrm{Cl}$-positive control. Only (C) showed wrinkled RBC. Inset corresponds to the photographs of hemolytic study. Hemoglobin was only released in the cells treated with $\mathrm{NH}_{4} \mathrm{Cl}$, confirming the biocompatibility of CuS NPs. Experiments were performed in triplicate.

carboxylesterase and brain acetylcholinesterase activity (Fig. S11 and S12†). Notably, the fish exposed to $10 \mu \mathrm{M}$ copper nanoparticles died in $2 \mathrm{~h}$, and there was a considerable reduction in the CES and AchE activity (Fig. S11 and S12†). This result clearly suggests that CuNPs are highly toxic, whereas CuS NPs are non-toxic.

Furthermore, the hemocompatibility of CuS NPs was studied by exposing the NPs to human red blood cells (RBC). As shown in Fig. 9, CuS NPs $(100 \mu \mathrm{M})$ do not induce any adverse change in RBC morphology (Fig. 9B) and the membrane is intact, like that of the control cells (Fig. 9A). However, $\mathrm{RBC}$ treated with $\mathrm{NH}_{4} \mathrm{Cl}$ are wrinkled (Fig. 9C) and undergo lysis to release hemoglobin, indicating that the membranes are damaged (inset of Fig. 9C). At the same time, no hemoglobin is released from the cells treated with CuS NPs (Fig. 9B and S13†), demonstrating intrinsic biocompatibility with human RBCs. These results suggest that NLTA-CuS NPs are quite safe and have excellent antibacterial activity against Gram-positive and Gram-negative bacteria.

\section{Materials and methods}

\subsection{Materials}

Copper chloride, hydrazine, ammonium hydroxide and sodium sulfide were obtained from Merck, India. Tyramine, laurylchloride, resazurin, dichlorofluorescein diacetate, acridine orange, ethidium bromide, 5,5'-dithiobis(2-nitrobenzoic acid), acetylcholine iodide, and naphthyl ethylenediamine hydrochloride were purchased from Sigma, India. $N$-Lauryltyramine (NLTA) was synthesized as per the reported protocol. ${ }^{7}$ All microbiological media were obtained from Himedia, India. Escherichia coli (MTCC723), Aeromonas hydrophila (MTCC1739T), Staphylococcus aureus (MTCC3160) and Bacillus subtilis (MTCC441) were obtained from the Institute of Microbial Technology, India. The organisms were preserved at $4{ }^{\circ} \mathrm{C}$ and sub-cultured at regular intervals of 30 days. All other chemicals and reagents were of the highest analytical grade and commercially available.

\subsection{Synthesis of copper sulfide nanoparticles}

To prepare CuS NPs, first, N-lauryltyramine (NLTA) capped copper nanoparticles were prepared according to the procedure described in ref. 7. In brief, $1 \mathrm{mg}$ of NLTA dissolved in $100 \mu \mathrm{L}$ of ethanol was added to $50 \mathrm{~mL}$ of $2.5 \mathrm{mM} \mathrm{NaOH}$ solution. Then, $1 \mathrm{mM}$ of copper chloride and $200 \mu \mathrm{L}$ of ammonium hydroxide were added to the solution. After $5 \mathrm{~min}$ of stirring at $600 \mathrm{rpm}$, $400 \mu \mathrm{L}$ of hydrazine hydride was added to the solution, following which the blue solution changed color and turned reddish brown in $6 \mathrm{~h}$. The obtained solution showed characteristic CuNP surface plasmon maximum at $580 \mathrm{~nm}$. The asobtained CuNPs were directly allowed to react with $1 \mathrm{mM}$ sodium sulfide for $3 \mathrm{~h}$ until a green solution was obtained, which suggests the formation of CuS NPs. Then, NLTA-CuS NPs were dialyzed (MWCO: $3 \mathrm{kDa}$ ) against water for $24 \mathrm{~h}$ before final use. The shape, size, crystallinity and elemental composition of the CuS NPs were investigated via transmission electron microscopy (TEM) and energy dispersive X-ray spectroscopy (EDX). For TEM, an aqueous solution of CuS NPs was drop casted on a graphite grid and air dried prior to analysis with TEM (JEOL JEM-2100F), operating at an accelerating voltage of $200 \mathrm{kV}$. EDX was measured on an FEI Quanta FEG 200 highresolution scanning electron microscope. For FTIR, NLTA and NLTA-CuS NPs were freeze dried and ground with $\mathrm{KBr}$ to form a pellet and measured in Perkin Elmer FTIR spectrometer with 1 $\mathrm{cm}^{-1}$ resolution.

\subsection{In vitro antibacterial activity of CuS NPs}

Gram-negative (E. coli, A. hydrophila) and Gram-positive ( $S$. aureus, B. subtilis) strains were used for the evaluation of antibacterial activity of CuS NPs. Bacterial cells were cultured aerobically for $12 \mathrm{~h}$ at $37^{\circ} \mathrm{C}$ in Luria-Bertani (LB) medium. The cultures were maintained by streaking on LB agar plates and incubated at $37{ }^{\circ} \mathrm{C}$ for $24 \mathrm{~h}$. Then, pure single colonies were isolated and subcultured every fortnight in a shaking incubator at $37^{\circ} \mathrm{C}$ until an optical density of $0.5-0.6$ at $660 \mathrm{~nm}\left(\mathrm{OD}_{660} \mathrm{~nm}\right)$ was reached.

To determine the minimum inhibitory concentration (MIC) of CuS NPs, $100 \mu \mathrm{L}$ of CuS NPs $(100 \mu \mathrm{M})$ was added to a 96-well plate and serially diluted and the final volume was made up to $100 \mu \mathrm{L}$ using LB medium. Then, $100 \mu \mathrm{L}$ of $1 \times 10^{5}$ cfu $\mathrm{mL}^{-1}$ bacterial cells were seeded into each well and cultured under shaking for $24 \mathrm{~h}$ at $37^{\circ} \mathrm{C}$. The $\mathrm{OD}_{660 \mathrm{~nm}}$ at each well was monitored using a Microtiter plate reader (Thermo Scientific Multiscan EX). Furthermore, cell viability was determined by adding $30 \mu \mathrm{L}$ of resazurin solution $(0.01 \% \mathrm{wt} /$ vol.) to each well and cultured for $2 \mathrm{~h}$ at $37^{\circ} \mathrm{C} .{ }^{45}$ The wells with viable cells showed color change from blue to pink and exhibited strong fluorescence. The fluorescence intensity in each well was monitored using a fluorescence microplate reader (Biotech, synergy H1, Japan), setting the excitation and emission at $530 \mathrm{~nm}$ and $580 \mathrm{~nm}$, respectively. The efficacy of CuS NPs was further judged by the zone of inhibition (ZOI) assay. Log-phase bacteria cells were swabbed uniformly on LB agar plates using sterile cotton swabs. Wells of $10 \mathrm{~mm}$ diameter were made on the plates using gel puncture. Using a micropipette, $50 \mu \mathrm{L}$ of $5 \mu \mathrm{M}, 10 \mu \mathrm{M}$ and $100 \mu \mathrm{M}$ CuS NPs were added to the respective wells and incubated at $37^{\circ} \mathrm{C}$ for $24 \mathrm{~h}$. The formation of the zone around the well confirms the antibacterial activity of CuS NPs. 


\subsection{Evaluation of therapeutic efficacy of CuS NPs in zebrafish}

To test the therapeutic efficacy, healthy zebrafish were infected with bacteria and then treated with CuS NPs. Zebrafish were kept in aerated glass tanks containing tap water at $25 \pm 2{ }^{\circ} \mathrm{C}$ and the infection was initiated through injecting bacterial cells into the fish body (details in ESI $\dagger$ ). ${ }^{46}$ The optimized bacterial dosage for intramuscular infection was $0.1 \mathrm{OD}_{660 \mathrm{~nm}}$. About 10 adult zebrafish were intramuscularly injected with $10 \mu \mathrm{L}$ of freshly prepared bacterial culture $\left(0.1 \mathrm{OD}_{660} \mathrm{~nm}\right)$ and allowed to survive with the infection for the next $3 \mathrm{~h}$. Then, the fish were divided into two groups, each group containing five fish. Fish in group A were labeled as infected controls and those in group B were treated by injecting $10 \mu \mathrm{L}$ of CuS NPs $(10 \mu \mathrm{M})$. In another method of treatment, group B fish were treated by exposing the intramuscular infected zebrafish to a water bath containing 10 $\mu \mathrm{M}$ CuS NPs. Mortality of the fish was monitored carefully for $48 \mathrm{~h}$. All experiments were performed in compliance with the CPCSEA guidelines for Laboratory Animal Facilities (Central Act 26 of 1982) and approved guidelines prescribed by the Institutional Animal Ethics Committee (IAEC, SASTRA University, India).

The infection in the fish tissue was analyzed by colony forming unit (cfu) counting. Typically, fish were sacrificed (anesthetized by $150 \mathrm{mM}$ MS-222 and euthanized by decapitation) at particular time intervals and the muscle tissue was dissected and homogenized in $1 \mathrm{~mL}$ of PBS buffer $(10 \mathrm{mM}$ phosphate, $150 \mathrm{mM} \mathrm{NaCl}, \mathrm{pH}-7.4)$. The homogenate was diluted $10^{-4}$ times and plated in triplicate on sterile LB agar plates and incubated at $37^{\circ} \mathrm{C}$ for $24 \mathrm{~h}$ and the bacterial colonies formed were counted and reported.

\subsection{Scanning electron microscopy imaging}

The changes in the bacterial morphology of the control (buffer treated) and CuS NP treated cells were analyzed via scanning electron microscopy (SEM) (Tescan Vega 3). For SEM sample preparation, bacteria $\left(1 \times 10^{5} \mathrm{cfu} \mathrm{mL}^{-1}\right)$ incubated with $10 \mu \mathrm{M}$ CuS NPs for $12 \mathrm{~h}$ were collected by centrifugation at $6000 \mathrm{rpm}$ for $3 \mathrm{~min}$ and fixed with $2.5 \%$ glutaraldehyde overnight at $4{ }^{\circ} \mathrm{C}$. After washing three times with PBS, the bacterial cells were dehydrated through sequential treatment with different percentage of ethanol for $15 \mathrm{~min}$. Then, cells were stained with gold sputtering for $35 \mathrm{~s}$ and imaged using SEM.

\subsection{Membrane integrity study}

The membrane integrity was evaluated by acridine orange (AO)/ethidium bromide (EB) double staining test. ${ }^{47}$ Briefly, bacteria $\left(1 \times 10^{5} \mathrm{cfu} \mathrm{mL}^{-1}\right)$ incubated with $10 \mu \mathrm{M} \mathrm{CuS} \mathrm{NPs} \mathrm{for}$ $12 \mathrm{~h}$ were collected by centrifugation at $6000 \mathrm{rpm}$ for $3 \mathrm{~min}$ at $4{ }^{\circ} \mathrm{C}$ and dual stained with $\mathrm{AO} / \mathrm{EB}$ for $2 \mathrm{~h}$ in the dark. After that, $10 \mu \mathrm{L}$ of the samples was placed on a glass slide with a coverslip and imaged under a fluorescence microscope (Nikon Eclipse). Green and red filters were used for AO and EB, respectively.

\subsection{Reactive oxygen species (ROS) test}

The generation of ROS was quantitatively estimated using dichlorofluorescein diacetate $\left(\mathrm{DCFH}_{2}\right.$-DA) assay. ${ }^{48}$ Typically, bacteria $\left(1 \times 10^{5} \mathrm{cfu} \mathrm{mL}^{-1}\right)$ incubated with different concentrations of CuS NPs for $12 \mathrm{~h}$ were collected by centrifugation at $6000 \mathrm{rpm}$ for $15 \mathrm{~min}$ at $4{ }^{\circ} \mathrm{C}$ and washed three times with PBS buffer. The pellet was re-suspended in $1 \mathrm{~mL}$ PBS buffer and incubated with $100 \mu \mathrm{M} \mathrm{DCFH} \mathrm{D}_{2}$-DA for $30 \mathrm{~min}$. After that, the cells were lysed with an alkaline solution, and the supernatant was collected by centrifugation at $6000 \mathrm{rpm}$ for $10 \mathrm{~min}$. The fluorescence intensity of the supernatant was measured in a fluorescence spectrophotometer using a $485 \mathrm{~nm}$ excitation wavelength and a $525 \mathrm{~nm}$ emission wavelength (JASCO spectrofluorometer FP-8200). Bacterial cells treated with $10 \mu \mathrm{M}$ hydrogen peroxide served as the positive control and untreated cells were considered as the negative control. The percent changes in fluorescence are expressed as follows:

$$
\begin{aligned}
\%= & {[(\text { sample }- \text { negative control }) /(\text { positive control }} \\
& - \text { negative control })] \times 100
\end{aligned}
$$

The generation of ROS was qualitatively imaged under a fluorescence microscope. First, E. coli (Gram-negative) and $B$. subtilis (Gram-positive) $\left(1 \times 10^{5} \mathrm{cfu} \mathrm{mL}^{-1}\right)$ were incubated with $10 \mu \mathrm{M}$ CuS NPs at $37^{\circ} \mathrm{C}$ for $12 \mathrm{~h}$. Then, the bacterial solutions were mixed with $100 \mu \mathrm{M} \mathrm{DCFH}_{2}$-DA and incubated for $30 \mathrm{~min}$ in the dark. After that, $10 \mu \mathrm{L}$ of the samples was placed on a glass slide with a cover-slip and observed under a fluorescence microscope using a green filter.

\subsection{Lipid peroxidation assay}

The production of ROS might damage the membranes and generate malondialdehyde (MDA). Thiobarbituric acid (TBA) assay was used to determine the MDA in the culture media. ${ }^{\mathbf{9}}$ Briefly, an aliquot of $1 \mathrm{~mL}$ of bacteria culture treated with CuS NPs was collected and mixed with $10 \%$ trichloroacetic acid. Then, $0.67 \%$ of TBA was added and incubated at $95{ }^{\circ} \mathrm{C}$ for $1 \mathrm{~h}$. The reaction mixture was cooled to room temperature and subjected to centrifugation at $6000 \mathrm{rpm}$ for $15 \mathrm{~min}$. The absorbance of the supernatant was measured at $532 \mathrm{~nm}$. Untreated cells and cells treated with $10 \mu \mathrm{M}$ hydrogen peroxide served as negative and positive controls, respectively. The percent of MDA production was determined according to eqn (1).

\subsection{Reduced glutathione (GSH) assay}

Excess generation of ROS may reduce intracellular concentration of GSH. GSH levels in the cells after treatment with CuS NPs $(0-10 \mu \mathrm{M})$ were estimated by 5-5'-dithiobis(2-nitrobenzoic acid) (DTNB) assay. ${ }^{50}$ Briefly, the cells were collected after NP treatment and lysed with $10 \%$ TCA solution for 15 min on ice. About $200 \mu \mathrm{L}$ of cell lysate was then mixed with $1800 \mu \mathrm{L}$ of Tris buffer (30 mM, pH 8.3) and $100 \mu \mathrm{L}$ of $0.1 \%$ DTNB solution and incubated for $90 \mathrm{~min}$ in the dark at room temperature. The absorbance was monitored at $412 \mathrm{~nm}$. Untreated cells and cells treated with $10 \mu \mathrm{M}$ hydrogen peroxide served as negative and 
positive controls, respectively. The total GSH level was estimated according to eqn (1).

\subsection{Evaluation of toxicity}

In vivo toxicity of CuS NPs was evaluated in a zebrafish model. Liver enzyme (carboxylesterase) and brain enzyme (acetylcholinesterase, AchE) were assayed. ${ }^{17}$ In a typical procedure, adult zebrafish were injected with $10 \mu \mathrm{L}$ of $10 \mu \mathrm{M}$ and $100 \mu \mathrm{M}$ CuS NPs and mortality, if any, was examined for a period of $48 \mathrm{~h}$. Fish injected with PBS served as controls. After $48 \mathrm{~h}$, fish from the control and NP treated groups were sacrificed and dissected carefully to collect liver and brain tissues. Then, the tissues were immediately homogenized in $1 \mathrm{~mL}$ of ice-cold PBS buffer and centrifuged at $10000 \mathrm{rpm}$ for $10 \mathrm{~min}$ at $4{ }^{\circ} \mathrm{C}$. The obtained supernatant was used in further studies.

Acetylcholinesterase assay was performed according to Ellman degradation protocol. ${ }^{51}$ Briefly, $100 \mu \mathrm{L}$ of brain homogenate was diluted with $900 \mu \mathrm{L}$ of PBS buffer and mixed with $50 \mu \mathrm{L}$ of $10 \mathrm{mM}$ DTNB solution. Then, $50 \mu \mathrm{L}$ of $12.5 \mathrm{mM}$ of acetylthiocholine iodide was added and incubated at $30^{\circ} \mathrm{C}$. After $5 \mathrm{~min}$, the reaction mixture turned yellow and the absorbance at $400 \mathrm{~nm}$ was measured on an ELISA plate reader (Thermo Scientific Multiscan EX). The activity was expressed as acetylcholine hydrolyzed per min.

The activity of $\alpha$-carboxylesterase and $\beta$-carboxylesterase was determined according to previously reported procedure. ${ }^{17}$ Briefly, $200 \mu \mathrm{L}$ of liver homogenate was diluted with $800 \mu \mathrm{L}$ of PBS buffer and mixed with $5 \mu \mathrm{L}$ of $250 \mathrm{mM}$ of $\alpha$-napthylacetate or $\beta$-napthylacetate and incubated at room temperature. After $30 \mathrm{~min}, 250 \mu \mathrm{L}$ of freshly prepared $0.3 \%$ Fast blue B in $3.3 \%$ SDS was added to the reaction mixture, leading to the development of dark blue color. After $30 \mathrm{~min}$, the absorbance of the blue color solution was measured at $430 \mathrm{~nm}$ and $588 \mathrm{~nm}$ for $\alpha$ - and $\beta$ carboxylesterase, respectively. The amount of $\alpha$ - and $\beta$-carboxylesterase was determined using the standard values and was reported as $\mathrm{mM}$ of $\alpha$ - and $\beta$-napthol released per min. All toxicity assays were performed in duplicate.

\subsection{Hemocompatibility test}

Biocompatibility of CuS NPs was investigated on red blood cells (RBC). In this work, human whole blood samples were collected by a trained doctor from volunteers in compliance with the institutional guidelines. Informed consent was obtained from the volunteers. Citrate stabilized blood samples were centrifuged at $6000 \mathrm{rpm}$ for $3 \mathrm{~min}$ and washed with PBS buffer. The collected RBC were resuspended in $10 \mathrm{~mL}$ of PBS buffer and used in further studies. About $100 \mu \mathrm{L}$ of RBC was mixed with $100 \mu \mathrm{M}$ CuS NPs and incubated at $37^{\circ} \mathrm{C}$ and $200 \mathrm{rpm}$ for $30 \mathrm{~min}$. The morphological changes in RBC were evaluated by placing $10 \mu \mathrm{L}$ of the cells on a non-grease glass slide and visualized under a microscope. In addition, the treated RBC and controls were centrifuged at $3000 \mathrm{rpm}$ and the absorbance of the supernatant was noted. RBC mixed with $100 \mu \mathrm{M} \mathrm{NH}_{4} \mathrm{Cl}$ and PBS served as positive and negative controls, respectively. All samples were prepared in triplicate at the same time.

\section{Conclusions}

In summary, the zebrafish animal model was adopted to understand the therapeutic efficacy of CuS NPs. Zebrafish infected with Gram-positive and Gram-negative bacteria were successfully treated with a medicated bath of CuS NPs. Treatment with CuS NPs depleted the infectious bacteria from the fish body within $24 \mathrm{~h}$ and completely cured them of the infection. Scanning electron microscopy imaging and fluorescence dye study confirmed that CuS NPs kill bacteria through membrane damage and CuS NPs trigger excess production of ROS, mediating oxidative damage over the GSH defense. Liver carboxylesterase and brain acetylcholinesterase activity of zebrafish remained unaffected even in the presence of high concentration of CuS NPs. Hemolytic assay confirmed that CuS NPs are hemocompatible. Being safer, further study with a rodent model would enable NLTA-CuS NPs for advanced clinical testing.

\section{Acknowledgements}

We thank Dr Thiagarjan for zebrafish toxicity study. We thank DST-FIST (SR/FST/ETI-331/2013) for fluorescence microscopy facility and the central research facility (R\&M/0021/SCBT-007/ 2012-13), SASTRA University for the infrastructure.

\section{References}

1 A. K. Thabit, J. L. Crandon and D. P. Nicolau, Expert Opin. Pharmacother., 2015, 16, 159-177.

2 B. D. Lushniak, Public Health Rep., 2014, 129, 314-316.

3 K. S. Kaye and J. M. Pogue, Pharmacotherapy, 2015, 35, 949962.

4 R. J. Fair and Y. Tor, Perspect. Med. Chem., 2014, 6, 25-64.

5 J. A. Lemire, J. J. Harrison and R. J. Turner, Nat. Rev. Microbiol., 2013, 11, 371-384.

6 K. P. Miller, L. Wang, B. C. Benicewicz and A. W. Decho, Chem. Soc. Rev., 2015, 44, 7787-7807.

7 A. Raghunath and E. Perumal, Int. J. Antimicrob. Agents, 2017, 49, 137-152.

8 D. Liang, Z. Lu, H. Yang, J. Gao and R. Chen, ACS Appl. Mater. Interfaces, 2016, 8, 3958.

9 Z. Lu, K. Rong, J. Li, H. Yang and R. Chen, J. Mater. Sci.: Mater. Med., 2013, 24, 1465.

10 J. Li, K. Rong, H. Zhao, F. Li, Z. Lu and R. Chen, J. Nanosci. Nanotechnol., 2013, 10, 6806-6813.

11 S. Wang, Q. Li, F. Chen, J. Ke and R. Chen, Adv. Powder Technol., 2017, 28, 1332-1339.

12 Z. Dai, F. Qin, H. Zhao, J. Ding, Y. Liu and R. Chen, ACS Catal., 2016, 6, 3180-3192.

13 F. Qin, H. Zhao, G. Li, H. Yang, J. Li, R. Wang, Y. Liu, J. Hu, H. Sun and R. Chen, Nanoscale, 2014, 6, 5402.

14 X. Zhong, Z. Dai, F. Qin, J. Li, H. Yang, Z. Lu, Y. Liang and R. Chen, RSC Adv., 2015, 5, 69312.

15 Y. Jia, S. Zhan, S. Ma and Q. Zhou, ACS Appl. Mater. Interfaces, 2016, 8, 6841. 
16 A. A. Khan Behlol, S. Megarajan, P. Suresh Kumar and V. Anbazhagan, Sens. Actuators, B, 2016, 233, 431-437.

17 U. S. Dharsana, M. K. N. Sai Varsha, A. A. Khan Behlol, V. Anbazhagan and R. Thiagarajan, RSC Adv., 2015, 5, 30248-30259.

18 L. Rene Christena, V. Mangalagowri, P. Pradheeba, K. B. Ayaz Ahmed, B. I. Sandhiya Shalini, M. Vidyalakshmi, V. Anbazhagan and N. Sai Subramanian, RSC Adv., 2015, 5, 12899-12909.

19 S. Megarajan, M. Vidhyalakshmi, A. A. Khan Behlol, M. Vandhith, B. R. S. Niranjani, N. Saisubramanian and V. Anbazhagan, RSC Adv., 2016, 6, 87513-87522.

20 Z. G. Cheng, S. Z. Wang, Q. Wang and B. Y. Geng, CrystEngComm, 2010, 12, 144-149.

21 H. Lee, S. W. Yoon, E. J. Kim and J. Park, Nano Lett., 2007, 7, 778-784.

22 Y. X. Zhao and C. Burda, Energy Environ. Sci., 2012, 5, 55645576.

23 R. Cai, J. Chen, J. X. Zhu, C. Xu, W. Y. Zhang, C. M. Zhang, W. H. Shi, H. T. Tan, D. Yang, H. H. Hng, T. M. Lim and Q. Y. Yan, J. Phys. Chem. C, 2012, 116, 12468-12474.

24 A. Šetkus, A. Galdikas, A. Mironas, I. Šimkiene, I. Ancutiene, V. Janickis, S. Kačiulis, G. Mattogno and G. M. Ingo, Thin Solid Films, 2001, 391, 275-281.

25 S. Goel, F. Chen and W. Cai, Small, 2014, 10, 631-645.

26 G. Ku, M. Zhou, S. Song, Q. Huang, J. Hazle and C. Li, ACS Nano, 2012, 6, 7489-7796.

27 Y. Huang, Y. Lai, S. Shi, S. Hao, J. Wei and X. Chen, Chem.Asian J., 2015, 10, 370-376.

28 H. Y. Wang, X. W. Hua, F. G. Wu, B. Li, P. Liu, N. Gu, Z. Wang and Z. Chen, ACS Appl. Mater. Interfaces, 2015, 7, 7082-7092.

29 S. Yu, J. Liu, W. Zhu, T. Hu, T. T. Lim and X. Yan, Sci. Rep., 2015, 5, 16369.

30 F. N. Oktar, M. Yetmez, D. Ficai, A. Ficai, F. Dumitru and A. Pica, Curr. Top. Med. Chem., 2015, 15, 1583-1588.

31 J. Ai, E. Biazar, M. Jafarpour, M. Montazeri, A. Majdi, S. Aminifard, M. Zafari, H. R. Akbari and H. G. Rad, Int. J. Nanomed., 2011, 6, 1117-1127.

32 I. Linkov, F. K. Satterstrom and L. M. Corey, Nanomedicine, 2008, 4, 167-171.

33 W. Ye, S. Abel, E. Andreas and L. Dusan, J. Mater. Chem. B, 2015, 3, 7153-7172.

34 C. A. MacRae and R. T. Peterson, Nat. Rev. Drug Discovery, 2015, 14, 721-731.
35 J. Barriuso, R. Nagaraju and A. Hurlstone, Clin. Cancer Res., 2015, 21, 969-975.

36 A. R. Willis, C. Moore, M. Mazon-Moya, S. Krokowski, C. Lambert, R. Till, S. Mostowy and R. E. Sockett, Curr. Biol., 2016, 26, 3343-3351.

37 I. H. Jain, L. Zazzeron, R. Goli, K. Alexa, S. Schatzman-Bone, H. Dhillon, O. Goldberger, J. Peng, O. Shalem, N. E. Sanjana, F. Zhang, W. Goessling, W. M. Zapol and V. K. Mootha, Science, 2016, 352, 54-61.

38 E. Tomaszewska, K. Soliwoda, K. Kadziola, B. TkaczSzczesna, G. Celichowski, M. Cichomski, W. Szmaja and J. Grobelny, J. Nanomater., 2013, 2013, 313081.

39 J. S. Kim, E. Kuk, K. N. Yu, J.-H. Kim, S. J. Park, H. J. Lee, S. H. Kim, Y. K. Park, Y. H. Park, C.-Y. Hwang, Y. K. Kim, Y. S. Lee, D. H. Jeong and M. H. Cho, Nanomedicine, 2007, 3, 95-101.

40 S. Chernousova and M. Epple, Angew. Chem., Int. Ed., 2013, 52, 1636-1653.

41 C. Carlson, S. M. Hussain, A. M. Schrand, L. K. B. Stolle, K. L. Hess, R. L. Jones and J. J. Schlager, J. Phys. Chem. B, 2008, 112, 13608-13619.

42 L. Masip, K. Veeravalli and G. Georgiou, Antioxid. Redox Signaling, 2006, 8, 753-762.

43 C. D. Vecitis, K. R. Zodrow, S. Kang and M. Elimelech, ACS Nano, 2010, 4, 5471-5479.

44 B. Ramalingam, T. Parandhaman and S. K. Das, ACS Appl. Mater. Interfaces, 2016, 8, 4963-4976.

45 S. D. Sarker, L. Nahar and Y. Kumarasamy, Methods, 2007, 42, 321-324.

46 M. N. Neely, J. D. Pfeifer and M. Caparon, Infect. Immun., 2002, 70, 3904-3914.

47 K. Liu, P. C. Liu, R. Liu and X. Wu, Med. Sci. Monit. Basic Res., 2015, 21, 15-20.

48 B. Kalyanaraman, V. Darley-Usmar, K. J. Davies, P. A. Dennery, H. J. Forman, M. B. Grisham, G. E. Mann, K. Moore, L. J. Roberts II and H. Ischiropoulos, Free Radical Biol. Med., 2012, 52, 1-6.

49 Y. J. Garcia, A. J. Rodríguez-Malaver and N. Peñaloza, J. Neurosci. Methods, 2005, 144, 127-135.

50 A. E. Cribb, J. S. Leeder and S. P. Spielberg, Anal. Biochem., 1989, 183, 195-196.

51 M. Benabent, E. Vilanova, M. Á. Sogorb and J. Estévez, MethodsX, 2014, 1, 258-263. 